\title{
A survey of goat production in the developing areas of the North West province of South Africa
}

\author{
E. Collins Lusweti ${ }^{\#}$ \\ University of the North West, Private bag X2046, Mmabatho 2735 South Africa
}

\begin{abstract}
The survey was carried out over two years in the Taung and Kudumane districts of the North West Province of South Africa. Data were collected on the breed of goat, reasons for keeping goats as well as production data such as kidding rate, fecundity, herd health care, herd management, live weight and withers height, coat color, skin condition and presence or absence of: beards, horns and wattles.
\end{abstract}

*Current address: University of Zululand, Private Bag X1001, Kwa Dlangezwa 3886, South Africa. E-mail: ecollins@pan.uzulu.ac.za

\section{Introduction}

Goats and sheep are integral components of animal farming systems in developing areas of Southern Africa. The aim of this survey was to generate data that could be used as a basis for designing and testing different on-farm strategies for improving small ruminant production in the North West Province.

\section{Materials and Methods}

The survey was carried out over two years in the Taung and Kudumane districts of the North West province. The data were derived from 244 Boer goats from five farms and 1254 Village goats from 31 farms. Data were collected on breed and type of goat, reasons for keeping goats, health care, management, fertility, fecundity, sex, mature weight, girth circumference, withers height, coat-color, skin condition and the presence or absence of beards, horns or wattles. Data were analyzed by analysis of variance (SAS System General Linear models procedure, SAS 1989) using the model shown in Equation 1 to determine the effects of breed and sex on mature: live weight ratio, girth circumference and withers height.

$$
\begin{array}{ll}
X_{\mathrm{ijk}}=m+A_{i}+B_{j}+A_{i} B_{j}+E_{i j k} & \text { Equation } 1
\end{array}
$$

$\left(m=\right.$ population mean; $A_{i}=$ discrete effect of breed; $B_{j}=$ discrete effect of sex; $A_{i} B_{j}=$ interaction effects of Breed and sex; $\mathrm{e}_{\mathrm{ijk}}=$ random error)

\section{Results and discussion}

Twins comprised $11 \%$ and $18 \%$ of kids born from Village and Boer goats respectively; the remainder was single-births. The most prevalent health problems recorded were pneumonia, internal parasites and nasal worms. Dipping was practiced on all farms surveyed and drenching was practiced in $90 \%$ of cases. Foot rot was recorded on $60 \%$ of farms. Eighty percent of farms did not reserve particular pastures for goats, and goats were not herded but were allowed to roam freely. Supplementary feeding was offered during winter on $80 \%$ of farms. Drought accounted for $20 \%$ and $3 \%$ of the stock losses in Boer and Village goats respectively; and predators and stealing together accounted for $80 \%$ and $52 \%$ of the losses in Boer and Village goats respectively. The major coat color in the Village goat was a mixture of brown, white and black. Boer goats had brown heads and necks, and the rest of the body was white. Eighty eight percent of Boer goats had horns, $83 \%$ had beards and $8 \%$ had wattles; in contrast, $30 \%$ of Village goats had horns, $52 \%$ had beards and $73 \%$ had wattles. Mean mature live weight for Boer goats was $35 \mathrm{~kg}$ (s.e. +10$)$, girth circumference was $71 \pm 13 \mathrm{~cm}$ and withers height was $60 \pm 7 \mathrm{~cm}$ respectively. For Village goats, mature live weight was $38 \mathrm{~kg}$ (s.e. \pm 9 ), girth circumference was $77 \pm 7 \mathrm{~cm}$ and withers height was $63 \pm 6 \mathrm{~cm}$.

Both sex and breed had significant $(p<0.01)$ effects on mature: live weight, girth circumference and withers height. There was a sex by breed interaction $(p<0.01)$ for mature: live weight, girth circumference and withers height. The average male: female ratio was 1:5 in Boer goat herds, and 1:4 in Village goat herds, indicating that a large proportion of mature males was retained. The main reasons given for keeping goats were for milk, meat and social functions. This could explain the high male: female ratios observed as males are mainly used for social 
(c) South African Society of Animal Science

occasions. There was also a clear indication that incentives for marketing goats were absent. Animals were not marketed at the most economic age: $25 \%$ of herds consisted of old males not required for breeding purposes. Most of the farms surveyed were situated in dry, stony, rocky areas with little grass cover and some acacia bushes on which goats browsed. Few other species of livestock could survive in these areas and on most farms and goats were left to fend for themselves.

\section{Conclusions}

Currently, goats in this area are kept for social reasons and for food security. It was concluded that commercial production of goats marketed at an optimum age could potentially improve the economy of small farmers in the North West province of South Africa, but health care would need to be improved and marketing incentives would need to be introduced.

\section{Reference}

SAS, 1989. Users guide version 6, first edition. SAS Institute Inc., Cary, NC. 